Linha D'Água (Online), São Paulo, v. 29, n. 2, p. 43-67, dez. 2016

\title{
O CONCEITO DE DOXA (OPINIÃO) EM ARISTÓTELES
}

\section{THE CONCEPT OF DOXA (OPINION) IN ARISTOTLE}

Christiani Margareth de Menezes e Silva*

Universidade Estadual de Londrina, Londrina, PR, Brasil

Resumo: A noção de doxa (opinião) será geralmente entendida por pensadores gregos como Platão como contrária ao conhecimento epistêmico, verdadeiro, devido a fato de expressar ou particularidades ligadas às percepcōes, que podem ser errôneas, ou a passionalidade dos sujeitos. Aristóteles, através da análise de um tipo de opinião, endoxa, que coincide com o verossímil na maioria das vezes, estabelecerá as espécies de opiniões que sevirĩo de base para argumentos dialéticos e retóricos.

Palavras-chave: Doxa. Endoxa. Retớrica. Dialética. Argumentação.

Abstract: The notion of doxa (opinion) will be understood by Greek thinkers like Plato as opposed to epistemic knowledge, true, due to the fact to be understood as an expression of particularities linked to perceptions, which may be erroneous, as well as express passionateness subjects. Aristotle, through the analysis of a type of opinion, endoxa, which coincide with the verisimilar most of the time, is who will establish the kinds of opinions that will be the base for dialectical and rhetorical arguments.

Keywords: Doxa. Endoxa. Rhetoric. Dialectic. Argumentation.

* Doutora da Universidade Estadual de Londrina - UEL, Londrina, PR, Brasil; christiani@uel.br 
Linha D'Água (Online), São Paulo, v. 29, n. 2, p. 43-67, dez. 2016

\section{Breve desenvolvimento da argumentação}

Para a maioria dos gregos, os embates entre opiniões (doxai) eram comuns nas argumentações das assembleias e tribunais, sendo parte de duelos discursivos e argumentativos típicos da cultura da época. É na cidade de Atenas que vemos o gosto pelos debates públicos aos poucos desenvolver artes da argumentação como a dialética e a retórica, o que talvez seja em parte devido a certa liberdade de expressão presente na polis ateniense. ${ }^{1}$

De acordo com Platão na obra Parmênides, Zenão de Eléia teria inventado a dialética - a arte de discutir perguntando e dando razões daquilo que se diz -, ao desenvolver argumentos em defesa das teses de seu mestre, Parmênides. Vemos na obra homônima de Platão Zenão apresentar argumentos que têm função semelhantes as das provas (tekmerion) dos debates jurídicos, ou seja, demonstrando uma verdade segura e irrefutável, enquanto a argumentação oposta expressa o contraditório e, consequentemente, é refutada e considerada errrônea.

Tal técnica da argumentação inventada por Zenão servirá para atacar qualquer tipo de tese, inclusive as de seu mestre Parmênides, ${ }^{2}$ como vemos o sofista Górgias fazer em seu Sobre o não-ser. O argumento central de Górgias nesse texto é demonstrar que o ser parmenídico é contraditório, e para isso ele diz que o ser não pode ser pensado nem dito, porque a palavra (logos) não exprime o ser, e nem pode conhece-lo, mas é ela própria que cria a realidade, tomando o lugar do ser. Isso aparece ainda em outro texto de Górgias, Elogio de Helena, no qual o logos não comunica conhecimento, mas sentimento, sendo compreendido por Platão e Aristóteles como contrário ao logos da dialética, e identificado com o logos da

\footnotetext{
Para uma apresentação da relação entre a liberdade de expressão e a democracia ateniense antiga, ver BERTI, Enrico. "A antiga dialética grega como expressão da liberdade de pensamento e de expressão". In Novos estudos aristotélicos I: Epistemologia, lógica e dialética. Trad. Élcio de Gusmão V. Filho. São Paulo: Loyola, 2010a. p. 392-409.

2 Para os argumentos contra o movimento e os paradoxos desenvolvidos por Zenão, ver MCKIRAHAN Jr. In. LONG, 2008, p. 191-218; BERTI, 2010b, p. 194-197; KIRK; RAVEN; SCHOFIELD, 2010, p. 275-292, entre outros. Sobre Zenão como inventor da dialética ver "Zenão de Eléia: inventor da dialética?" (BERTI, 2010a, p. 411-431). Sobre as questões relacionadas à noção de "ser" no pensamento grego, ver os artigos presentes em KAHN, Charles H. Sobre o verbo grego ser e o conceito de ser. Tradução de AAVV. Rio de Janeiro: PUC-Rio, 1997.
} 
retórica sofística, que visa persuadir movendo os afetos. Vemos Platão apresentar um exemplo dessa força da linguagem quando faz Górgias na obra homônima dizer que mesmo não sendo ele médico, consegue convencer os pacientes a adotarem o tratamento recomendado por seu irmão, este sim médico (Górgias 456 b)! Assim, o logos é o grande dominador (dynastes) ao qual a maioria não resiste (Elogio de Helena, 19), não comunicando a verdade, mas a criando e persuadindo passionalmente seus ouvintes. ${ }^{3}$

Outra característica criticada por Platão na retórica dos sofistas é o fato deles preferirem "discursos longos", sem participação de interlocutores, como seria o caso dos discursos dialéticos, estes sim discursos "breves" e com a constante presença de interlocutores. Porém, no diálogo Protágoras, o personagem título, um sofista, é descrito por Platão como alguém que prefere o discurso breve, fato raro entre os oradores; então Protágoras aceita perguntar e dar razão do que diz - algo característico também da dialética -, enquanto a retórica, como Platão a caracteriza, ao utilizar discursos longos, faz esquecer as razões, sem apresentar passo a passo o que afirma.

Apesar disso, Protágoras é considerado por Platão um professor de retórica ou sofista hábil tanto no discurso breve como no longo (Protágoras, 335 b-c); parece que Protágoras pretendia em suas argumentações apresentar a credibilidade de pontos de vistas opostos, o que tornaria impossível decidir qual ponto de vista seria falso e qual seria verdadeiro, concluindo dessa maneira, que ambos fossem verdadeiros; assim, ambas as opiniões (doxai) se equivaleriam (Teeteto, 166 dss.). Isto é consequência da famosa doutrina do homo mensura - "o homem como medida de todas as coisas”-, ou da equipolência das teses, interpretada por Platão e Aristóteles como uma doutrina relativista, porque torna a contradição e a refutação impossíveis ao não permitir a dedução da contradição em teses contrapostas (Cf. Eutidemo, 286 b-c).

3 Devemos lembrar que o termo sophistes (sofista) não apresenta na época uma conotação pejorativa, significando "sábio", e que essa é dada pela interpretação de alguns autores, dentre os quais Platão, seguida por Aristóteles. Para uma apreciação inicial dessa questão, remeto o leitor a WOODRUFF, Paul. "Retórica e relativismo: Protágoras e Górgias" e CAIZZI, Fernanda D. "Protágoras e Antifonte: Debates sofísticos acerca da justiça" (LONG, 2008, p. 365-388; e p. 389-411). 
Contemporâneo dos sofistas e de alguns dos primeiros filósofos, Sócrates fará uso das práticas discursivas típicas da dialética em suas inquirições nas ruas de Atenas, mas apesar de utilizar algo que os sofistas desenvolveram, ele imprime à dialética outra configuração, na qual a opinião não terá o mesmo peso que tem para Protágoras, por exemplo. De acordo com Platão, Xenofonte e Aristóteles, ${ }^{4}$ Sócrates praticava um método de discussão via perguntas e respostas para refutar seu interlocutor, conhecido como elenchus (refutação). Com Sócrates a dialética se distingue da retórica, especialmente em relação à forma de considerar as opiniões, pois a dialética propõe um método de análise crítica das mesmas, enquanto a retórica, como a protagoriana, as considera verdadeiras, cabendo ao orador tornar uma delas persuasiva. Mesmo distinta na forma de considerar a opinião, a dialética mantém-se no terreno das opiniões para Sócrates, embora relacionada com a ciência, mas com esta não se identificando, como percebemos nos primeiros diálogos inconclusos de Platão, conhecidos como “diálogos socráticos” ou aporéticos.

Sinteticamente, o método socrático do elenchus consiste em ser:

[...] um procedimento dialético no qual, ao contrário de uma demonstração científica aristotélica, onde partimos de premissas apodíticas e chegamos a uma conclusão necessária, partimos de uma proposição aceita pelo interlocutor com o intuito de testá-la em conjunto com outras crenças do mesmo interlocutor de modo a verificar a consistência do conjunto (DINUCCI, 2008, p. 5).

O elenchus socrático é, portanto, um método de verificação da consistência das opiniões, demonstrando que essas não constituem conhecimento verdadeiro, embora Sócrates não nos indique nesses diálogos aporéticos em que consiste a ciência, apenas que opinião não é ciência ou conhecimento epistêmico.

4 Os testemunhos, e a descrição do método praticado por Sócrates, encontramos em Xenofonte Memoráveis (ver bibliografia), em várias obras de Platão e sua teorização é feita nas Refutações Sofísticas e nos Tópicos de Aristóteles. Os diálogos entendidos como ligados ao Sócrates histórico, ou diálogos socráticos, escritos por Platão, são os seguintes: Apologia de Sócrates, Cármides, Críton, Eutífron, Eutidemo, Górgias, Hípias Menor, ĺon, Lísis, Laques, Protágoras, o Livro I da República e a primeira parte do Mênon. Destes diálogos, apenas a Apologia é, em grande parte, um monólogo de Sócrates defendendo-se no tribunal de Atenas, os demais são diálogos entre Sócrates e interlocutores. Conforme grande parte dos especialistas, é muito provável que a dialética característica desses diálogos fosse praticada pelo Sócrates histórico. 
Linha D'Água (Online), São Paulo, v. 29, n. 2, p. 43-67, dez. 2016

Será Platão, seu discípulo, que indicará a saída das aporias presentes nos primeiros diálogos e fará a distinção entre opinião e ciência, identificando esta última com a dialética.

\section{Platão: Oposição opinião-ciência}

No diálogo Mênon, da fase intermediária de seu pensamento, a dialética é relacionada à ciência, embora Platão ainda não identifique as duas, o que ele faz em uma obra sua da maturidade, República. ${ }^{5}$ Nesta obra, especialmente na descrição dos estados do conhecimento no final do Livro VI, passagem conhecida como "Símile da Linha” ou "Linha Dividida", Platão, na voz de Sócrates, descreve os dois planos do real e atribui a eles graus de conhecimento, identificando a dialética com a ciência, assim como o lugar da opinião no processo de conhecimento.

A questão do conhecimento aqui passa pelo famoso dualismo da realidade platônico, isto é, a distinção entre dois planos do real, a saber: o sensivel e o inteligivel, sendo este último causa (aitia) do primeiro. A Linha (509 d-511 e), como exposta por Sócrates, é dividida primeiramente em duas partes desiguais correspondentes aos dois planos da realidade, sendo subdividida em cada um desses segmentos em segmentos intermediários. Sua divisão dá-se conforme uma determinada relação e, segundo Pierre Aubenque, os dois segmentos intermediários são iguais. ${ }^{6}$ Assim, na divisão feita por Sócrates em 509d, sabemos que inicialmente a

5 No Teeteto, Platão fala da "opinião verdadeira", que é uma possibilidade, mas, por não termos como saber se a possuímos em todos os casos, toda opinião deve ser recusada como expressando algo verdadeiro, já que não há garantias de que opinião e verdade coincidam sempre, já que quando coincidem é acidentalmente.

6 A consideração da divisão da linha em partes iguais, foi abandonada pela maioria dos comentadores desde John Burnet, como nos esclarece Pierre Aubenque em seu artigo: "De l'egalité dês segments intermédiaires dans la ligne de la Republique", In Sophies Maietores, Homnage a Jean Pépin, 1992, 31-44. Aubenque ainda esclarece que tal desigualdade apresenta como argumento de fundo o fato de serem as regiões do sensível e do inteligível, ali representadas, regiões desiguais, permanecendo em aberto a qual das duas caberia o segmento mais longo. E outro argumento apresentado por Aubenque é de ordem matemática, pois se a intenção aqui é construir uma proporção, uma analogia, então não há porque esta ser reduzida a uma igualdade aritmética, já que a analogia seria de tipo $1 / 1=1 / 1$ e resultaria em $1=1$, o que, segundo Aubenque faria peder a função própria da analogia, a saber: "pensar a igualdade de relações entre termos desiguais" (AUBENQUE, op. cit., p. 38-39). 
Linha D'Água (Online), São Paulo, v. 29, n. 2, p. 43-67, dez. 2016

linha é dividida desigualmente em dois segmentos, um correspondente ao sensível e outro à realidade inteligível. Logo a seguir, Sócrates faz corresponder ao plano do sensível e ao plano do inteligível, níveis de conhecimento, ou seja, à divisão entre o mundo dos sentidos e o mundo inteligível cabe uma subdivisão associada aos quatro estados (pathemata) da alma quanto ao que se conhece em cada seguimento de ambas as realidades, sensível e inteligível.

Dessa forma, em relação ao sensível, tem-se apenas o conhecimento das opiniões, ou seja, as doxai, formadas inicialmente com o que primeiro temos do sensível, isto é, a percepção das sombras e dos reflexos das coisas sensíveis, correspondentes à eikasia, das quais fazemos no máximo conjecturas (República, 509d-510a). As coisas sensíveis, que provocam sombras e reflexos, aparecem após a eikasia (conjectura) são os artefatos humanos e os seres vivos (animais e plantas) que correspondem à pistis, ou seja, a crença que colocamos naquilo que vem da sensação (aisthesis) (República, 510a). Na eikasia, por percebermos apenas sombras e reflexos das coisas sensíveis, temos um conhecimento mais obscuro do que na pistis, pois nela percebemos as próprias coisas sensíveis (IGLÉSIAS, 1998, p. 48). Essa distinção, portanto, entre ver um graveto na água, por exemplo, e vê-lo fora dela implica um maior grau de clareza, pois uma coisa é ver o objeto e outra bem diferente é ver o seu reflexo ou sua sombra (ibid., p. 49). Portanto, no plano do sensível, o máximo de conhecimento que atingimos se baseia nas opiniões (doxai) acerca daquilo que os sentidos captam via eikasia e pistis, sem alcançarmos um conhecimento seguro e verdadeiro, pois o sensível é considerado por Platão uma cópia imperfeita, mutável, instável do verdadeiro encontrado apenas no plano inteligível.

$\mathrm{Na}$ descrição do segmento inteligível, Sócrates também apresenta divisões, assim como no sensível, embora a distinção que neste é clara em relação ao que corresponde à pistis e ao que corresponde à eikasia, resultando em um conhecimento opinativo (doxa), não é assim tão clara no texto platônico em relação ao inteligível, porque pelo texto não há como sabermos se entre os objetos matemáticos (presentes na primeira parte do segmento inteligível) e as Ideias/Formas (idea/eidos) propriamente ditas existe uma diferença ontológica. Deixando esta questão de lado, por ela ser complexa e extrapolar nosso objetivo aqui, devemos observar que no primeiro segmento do inteligível, a análise feita estabelece 
Linha D'Água (Online), São Paulo, v. 29, n. 2, p. 43-67, dez. 2016

hipóteses e, a partir dessas análises procuramos chegar a uma conclusão hipotética. Já no segundo segmento do inteligível, também utilizamos hipóteses, mas não procuramos mais conclusões provisórias, hipotéticas, pois objetiva-se chegar ao princípio (ousia) ou princípios sem se apoiar no uso de imagens, apenas nas Ideias ou Formas (República, 510b). Na dianoia, o primeiro grau de conhecimento dessa etapa, os resultados obtidos ainda não levam ao inteligível, embora este seja visado. As hipóteses aqui obtidas chegam a um princípio, que é considerado hipotético e não absoluto e depois dessas serem cuidadosamente examinadas chega-se ao princípio não hipotético $(i d$.$) .$

No procedimento dialético como entendido por Platão, o que se procura é o princípio e passamos gradualmente de hipótese em hipótese até se chegar ao não hipotético. Chegando a esse ponto a razão passa então "de Idéia em Idéia para chegar a uma Idéia.” (IGLÉSIAS, 1998, p. 50; República, 511 b) Mas como isso se dá - chegar ao não hipotético -, Platão esclarece apenas em outra obra sua, Fédon. Não nos alongaremos mais nessa questão, já que nos interessa aqui a postura que Platão tem diante das opiniões, sua desvalorização e distinção da ciência, e a identificação desta com a dialética, pois:

Para Platão, o 'refutar segundo a opinião' praticado por Protágoras não se caracteriza mais com a dialética, visto que esta última deve 'refutar segundo a realidade': logo, não há outra dialética senão a filosofia, uma filosofia entendida como ciência. (BERTI, 2010b, p. 404)

Portanto, a doxa, mesmo quando verdadeira (Teeteto) não é o terreno do conhecimento epistêmico e objetivo para Platão. Mesmo reconhecendo que o tipo de argumentação sofística, ou algumas figuras dessa como o elenchus, deva ser levada a sério, é só observarmos as várias obras de Platão nas quais a retórica está em pauta, ele só reconhecerá valor à retórica quando a aproximar de seu método epistêmico, a dialética como ocorre no Fedro, e mesmo nesse caso, a opinião é refutada por ligar-se ao terreno do passageiro e revelar posições singulares que pouco, ou quase nada, contribuem para o âmbito do conhecimento objetivo, necessário e universal. Veremos a seguir que para Aristóteles a opinião, ou certo tipo dela, será base para as argumentações da retórica, assim como da dialética, mas no estagirita 
Linha D'Água (Online), São Paulo, v. 29, n. 2, p. 43-67, dez. 2016

esta última não será mais sinônimo de episteme e filosofia como em Platão, e a retórica será uma arte (techne) da linguagem, como a dialética.

\section{Um tipo especial de opinião: os endoxa}

Como aludimos antes, em Aristóteles a opinião terá papel central nas esferas da dialética e da retórica, além de servir também às ciências particulares e às filosóficas. Diferentemente de seu mestre Platão, Aristóteles atribui outro papel à dialética em seu pensamento e não a identifica com a ciência (episteme), embora a dialética esteja a ela associada por possibilitar a análise dos princípios, algo que a ciência não faz.

É interessante lembrar que Aristóteles contrapõe as opiniões dos filósofos no início de sua Metafísica, quando analisa as teses de seus predecessores, indo de Tales a Platão, à luz de sua teoria das quatro formas ${ }^{7}$. As teses dos filósofos, contudo, não são para Aristóteles os tipos de opiniões expressas nas discussões dialéticas e retóricas, pois essas esferas são constituídas para ele por uma classe especial de opiniões conhecidas como endoxa, adjetivo grego que expressa não uma opinião qualquer, mas aquela ou aquelas opiniões que têm "fama", "reputação", "glória" (BERTI, 2002, p. 25), isto é, as opiniões dos mais sábios ou eminentes, ou opiniões comuns à maioria.

Nos Tópicos, tratado aristotélico sobre a dialética, Aristóteles procura os topoi (lugares) ou esquemas de raciocínio úteis para a argumentação:

Nosso tratado se propõe encontrar um método [methodos] de investigação graças ao qual possamos raciocinar, partindo de opiniões geralmente aceitas [endoxa], sobre qualquer problema que nos seja proposto, e sejamos também capazes, quando replicamos a um argumento, de evitar dizer alguma coisa que nos cause embaraço. ${ }^{8}$

7 Como observado por J. Mansfield, em um texto sobre o princípio da filosofia grega, na passagem em que trata da recepção de Aristóteles dessa herança: MANSFIELD, Jaap "Fontes". In LONG, A. A. (Org.) Primórdios da Filosofia. Tradução de Paulo Ferreira. Aparecida, SP: Idéias \& Letras, 2008. p. 74. (Companions \& Companions)

8 Tópicos | 1, 100 a 18-22. Tradução de Leonel Vallandro e Gerd Bornheim da versão inglesa de W. D. Ross. São Paulo: Abril Cultural, 1973. (Os Pensadores IV) Uso esta tradução nas citações dessa obra, geralmente com modificações, mas não na presente passagem citada. 
A dialética constrói suas premissas e proposições baseando-se nas "opiniões geralmente aceitas" (endoxa), que são opiniões, como dissemos, de tipo especial, porque elas dizem respeito a um corpo de crenças expressas, e é no interior destas que elas se elegem e se justificam: “São, por outro lado, opiniões 'geralmente aceitas' [endoxa] aquelas que todo mundo admite, ou a maioria das pessoas, ou os sábios [sophoi] - em outras palavras: todos, ou a maioria, ou os mais notáveis e eminentes [endoxoi]."

Assim, a dialética aristotélica desenvolve a argumentação no plano das opiniões comuns à maioria, e é neste plano que se encontra sua veracidade (Tópicos I 14, 105 b30-31). Dessa forma, o plausível (endoxon), objeto da opinião comum, é identificado por Aristóteles com o provável (eikos), que, sem ser necessário, contém verdade, pois ele é assim reconhecido pela maioria (boi pleitoi), ou, pelo menos, pelos mais sábios (hoi sophoteroi; Tópicos I 10,104 a8). Além disso, a dialética para Aristóteles seleciona e justifica os endoxa e não é uma arte da controvérsia entre opiniões, onde encontramos para ele a erística; ela é um cálculo de probabilidades ${ }^{10}$ que estabelece quais opiniões são endoxa e quais são seu contrário, as adoxon, opiniões compartilhadas por poucos, ou pelos menos sábios (Tópicos I 10, 100 b23-101 14).

Pois nem toda opinião que parece geralmente aceita o é na realidade. Com efeito, em nenhuma das opiniões que chamamos geralmente aceitas, a ilusão é claramente visível [epi polaion echei pantelos ten phantasian], como acontece com os princípios dos silogismos erísticos, nos quais a natureza da falácia é de uma evidência imediata, e em geral até mesmo para as pessoas de pouco entendimento. (Tópicos I 1, 100 b26-101 a1)

9 Tópicos 1, 100 b2 1-23. Tradução de Leonel Vallandro e Gerd Bornheim com modificações. Preferi traduzir sophoi por "sábios" por concordar com os comentadores que apontam o fato de que estes não coincidem com os filósofos, já que as opiniões destes podem não ser compartilhadas pela maioria, não se caracterizando, portanto, como endoxa. Estes sophoi são geralmente os especialistas em uma determinada área, por exemplo, no caso de geômetras, quanto à geometria, e dos médicos, quanto à medicina.

10 Cf. VIANO, G. apud. RACIONERO, Quintín. "Introduccíon" In ARISTÓTELES, Retórica. Introdução, Tradução e Notas de. Madrid: Gredos, 1994. p. 35. O eikos (provável ou plausível) era o esquema argumentativo comumente ensinado pelos sofistas, sendo identificado por Platão com aquilo que esses rétores ofereciam no lugar da verdade. Cf. WOODUFF, P. "Retórica e relativismo: Protágoras e Górgias" In LONG, A. A. (org.) Primórdios da Filosofia. Trad. Paulo Ferreira. Aparecida, SP: Idéias \& Letras, 2008. (Companions \& Companions) p. 372. 
Linha D'Água (Online), São Paulo, v. 29, n. 2, p. 43-67, dez. 2016

Para Aristóteles os endoxa expressam um fundo real de sabedoria em linguagem já construída e reconhecida pela maioria, ou pelos especialistas. Eles são, assim, as próprias premissas ou proposições dialéticas, como ele diz expressamente ao definir essas proposições nos Tópicos:

[...] uma proposição dialética consiste em perguntar alguma coisa que é admitida por todos os homens, pela maioria deles ou pelos sábios [sophoi], isto é, ou por todos, ou pela maioria, ou pelos mais eminentes, contanto que não seja contrária à opinião geral; pois um homem assentirá provavelmente ao ponto de vista dos sábios se este não contrariar as opiniões da maioria das pessoas. (Tópicos 10, 104 a 9-12)

Quando nos encontramos diante de uma pergunta que apresenta duas possibilidades contraditórias de respostas estamos diante de um tipo de problema dialético (problema dialekikon) para Aristóteles: "Os problemas [dialéticos] também incluem questões em relação às quais os raciocínios se chocam (consiste então a dificuldade em se tal ou tal coisa é ou não é assim, havendo argumentos convincentes a favor de ambos os pontos de vista)" (Tópicos I 11, 104 b11-15). Se na discussão desse tipo de problema alguém der uma resposta que contradiga a opinião comum (endoxa), a resposta dada é paradoxal (paradoxos), como acontece com as opiniões dos filósofos, e por isso tais opiniões não coincidem com os endoxa. É só lembrarmos que as opiniões dos filósofos não eram na época compartilhadas pela maioria, eram mesmo motivo de controvérsia (BERTI, 2010a, p. 370-371).

Já as opiniões dos peritos ou especialistas (teknites) podem ser endoxa, e as proposições formadas a partir delas se harmonizam para Aristóteles com as artes (technai):

[...] todas as proposições que se harmonizam com as artes [kata technas] são proposições dialéticas; pois os homens estão predispostos a dar seu assentimento aos pontos de vista daqueles que estudaram essas coisas: por exemplo, numa questão de medicina concordarão com o médico, numa questão de geometria, com o geômetra; e da mesma forma nos outros casos. (Tópicos 10, 104 a33-37) 
Opiniões como as dos geômetras e médicos, especialistas em suas áreas, são endoxa, assim como opiniões compartilhadas pela maioria. Como esclarece Berti, as premissas dialéticas, por serem endoxa, se dispõem em ordem decrescente de autoridade, "se a propósito de um problema houver uma opinião aceita por todos, esta será o endoxon, se não houver uma opinião aceita por todos, mas apenas pela maioria, o endoxon será esta, e assim por diante." ${ }^{11}$ Uma premissa endoxa pode ser verdadeira ou falsa, entretanto, ela deve ser compartilhada por uma maioria, ou pelo menos por especialistas. Além disso, as premissas dialéticas são endoxa porque devem ser compartilhadas pelo interlocutor, ou pela plateia que assiste ao debate, como era comum na antiguidade grega.

Se, como dissemos antes, a característica das premissas dialéticas é expressar opiniões de tipo endoxa, a confutação de uma solução e a validação de sua oposta depende do valor de verdade das premissas. Se estas são verdadeiras, não há o que opor, mas se são premissas que podem não ser verdadeiras, sua confutação tem um valor relativo para o interlocutor. Por isso a importância de estabelecer o valor de verdade, ou valor epistemológico dos endoxa: segundo Enrico Berti é ao distinguir endoxa autênticos de endoxa aparentes, que Aristóteles esclarece o valor de verdade ou valor epistemológico destes nos Tópicos. Os endoxa autênticos são premissas dos silogismos dialéticos e os aparentes são, por outro lado, premissas dos silogismos erísticos ou sofísticos, sendo, portanto, superficiais, enquanto os endoxa autênticos são verdadeiros na maioria dos casos.

\section{Opinião, dialética e retórica}

Apesar de tais explicações no seu trabalho sobre dialética, é em sua Retórica que o valor de verdade ou valor epistemológico dos endoxa é esclarecido por Aristóteles mais que nos Tópicos (cf. BERTI, 2010a, p. 374). A primeira parte da Retórica, Livro I capítulos 1 e 2, apresenta muita semelhança com os Tópicos, especialmente o Livro I 1-2 deste. Esta proximidade entre retórica e dialética parece se dever

\footnotetext{
11 BERTI, 2010a, p. 370. Berti parafraseia J. Brunschwig em Dialetique et philosophie. Berti inclusive lembra que o neologismo "endoxa" foi cunhado por Brunschwig, para ser contraposto a "paradoxal".
} 
Linha D'Água (Online), São Paulo, v. 29, n. 2, p. 43-67, dez. 2016

à fundamentação da retórica como uma verdadeira techne da linguagem. ${ }^{12}$ Além disso, a retórica é também considerada como "o desdobramento" ou "a outra face" (antistrophos) da dialética (BERTI, 2010a, p. 406).

A retórica é a outra face [antistrophos] da dialética; pois ambas se ocupam de questões mais ou menos ligadas ao conhecimento comum e que não pertencem a nenhuma ciência em particular. De fato, todas as pessoas de alguma maneira participam de uma ou de outra, pois todas elas tentam em certa medida questionar e sustentar um argumento, defender-se ou acusar. ${ }^{13}$

A dialética e a retórica são disciplinas paralelas que lidam com as opiniões, são técnicas ou artes (technai) da linguagem em Aristóteles que se complementam, mas não se identificam, e a função de ambas é selecionar e justificar enunciados prováveis para assim constituir raciocínios verossímeis. Elas são methodoi,

12 Cf. MOST, 1994, passim; BERTI, 2010a, 373-387. O artigo de Most é pioneiro na análise do valor epistemológico dos endoxa na Retórica. Techne, arte, técnica ou perícia, é uma noção próxima à episteme (ciência) entre os antigos, sendo geralmente sua sinônima em Platão e em algumas passagens da obra de Aristóteles. Apesar disso, Aristóteles estabelece mais claramente a diferença entre essas noções: a techne é um tipo de saber teorético, e por isso epistêmico, que pode ser aplicado, como também ensinado, já que é característica do especialista, assim como do cientista, saber o porquê e a causa, o que os capacita a ensinar para Aristóteles. No processo de conhecimento descrito no início da Metafísica, que vai da sensação (aisthesis) à episteme, apenas esta e a techne são conhecimentos universais, enquanto aisthesis, mneme (memória) e empeiria (experiência) o são dos particulares. $O$ teknites, especialista, perito, técnico, artista, são médicos, arquitetos, sapateiros, navegadores, poetas, entre outros (Ver PUENTE, Fernando Rey. A téchne em Aristóteles. Hypnos, ano 3, n. 4, p. 129-135). Para o esclarecimento dessas questões em Aristóteles, ver as distinções feitas na Ética a Nicômaco VI. É curioso notar que os textos que tratam de technai em Aristóteles - Tópicos, Retórica e Poética - dizem respeito a artes que se dão por meio da linguagem.

13 Retórica I 1, 1354 a 1-7. Tradução M. Alexandre Jr., P. F. Alberto e A. N. Pena, modificada. Lisboa: Imprensa Nacional/Casa da Moeda, 1998. O termo antítrofe vem do teatro e significa uma cumplicidade formal comum à retórica e à dialética: e rhetorike estin antistrophos te dialektike (Retórica 1354 a 1-2). Antistrophos é traduzido geralmente por "correlativo": "Na lírica coral, a estrutura métrica de uma strophe repete-se na antistrophe, representando a primeira o movimento numa direcção, e a segunda o movimento contrário. Ambos, porém, em coordenação oposta e complementar, como artes que têm semelhanças gerais e diferenças específicas." Cf. ALEXANDRE JÚNIOR, M.; ALBERTO, P. F.; PENA, A. N., 1998, nota 2, p. 89. Literalmente significa "convertível", correspondente, paralela, análoga. Cf. BERTI, 2002, p. 171. A retórica é também considerada "imagem" (homoima), "semelhante" (homoia) à dialética. Cf. Retórica 1359 b1 1 e 1354 a31, respectivamente. Ela também é paraphyes (ramo); ver nota abaixo. 
instrumentos que determinam os requisitos que as argumentações prováveis devem cumprir, apresentam o mesmo objeto e o mesmo tipo de saber, mas o âmbito de aplicação de ambas não se restringe a alguma matéria ou fim determinado (Retórica I 1, 1355 b8-10).

Cabe à dialética examinar (exetazein) e sustentar um argumento (bypechein logon), e cabe à retórica acusar (kategorein) e defender (apologeisthai) (Retórica 1354 a5-6). Como já consideramos, a retórica e a dialética são antístrofes ou saberes simétricos e complementares, e não redutíveis um ao outro (Retórica 1354 a1-3; Refutaçôes Sofísticas 34,183 b1-8), já que além de antistrophe, a retórica é paraphyes, isto é, um ramo ou ramificação autônoma da dialética (e da política): "a retórica é como que um ramo [paraphyes] da dialética e daquele saber prático sobre os caracteres a que é justo chamar política" (Retórica I 1, 1354 a1-10). ${ }^{14}$

Assim, a dialética deve saber provar a probabilidade de uma opinião, refutando as opiniões opostas objetivando vencer uma discussão; enquanto a retórica deve saber defender a opinião mais provável, determinando, mediante persuasão, a necessidade da aceitação de tal opinião pelo público, que julga calado, o discurso proferido pelo orador. $\mathrm{O}$ paralelismo entre retórica e dialética se deve ainda ao fato de ambas possuirem a mesma estrutura: a forma e a argumentação via silogismo, o que as torna ainda análogas da ciência apodítica ou demonstrativa (episteme). ${ }^{15}$ Em suma, ambas são artes ou técnicas (technai) que constroem seus argumentos

14 termo paraphyes, comum na biologia aristotélica, parece indicar a independência do ramo cortado da planta, ou o membro de um animal, em relação ao todo do organismo. Utilizado aqui de maneira metafórica, indicaria que, mesmo independente, a retórica é parte da filosofia prática de Aristóteles, a saber: da dialética, da ética e da política Cf. RACIONERO, 1994, nota 38, p. 178-179.

15 Encontramos a definição de ciência (episteme), nos Segundos Analíticos: "Julgamos conhecer cientificamente (epistasthai) cada coisa, de modo absoluto e não, à maneira sofística, por acidente, quando julgamos conhecer a causa pela qual a coisa é, que ela é a sua causa e que não pode essa coisa ser de outra maneira" (| 2, 71 b9-12) Tradução de PEREIRA, 2000, p. 35. A causa (aitia) no sentido antigo e aristotélico significa o porquê ou qualquer tipo de explicação: se é para explicar um objeto, pergunta-se do que ele é feito (causa material), porque é feito de certo modo e não de outro (causa formal), quem o fez (causa eficiente) e para que serve (causa final). Se o que se quer explicar é um evento pergunta-se por que aconteceu, o que o provocou, por que se apresentou daquele modo e não de outro, que consequências ele pode ter, a que fins pode estar voltado. Em sentido moderno, causa coincide apenas com a causa de tipo eficiente aristotélica (CF. BERTI, 2010b, p. 10). 
partindo de opiniões de tipo endoxa e mantém a estrutura típica dos argumentos para Aristóteles, a silogística.

O caráter técnico da retórica é saber utilizar, da melhor maneira, as pisteis, ou seja, os meios de persuasão, os modos de causar crença, as provas (1354 a13, 1355 a4). Como arte (techne) da linguagem que é a retórica lida com a construção argumentativa do discurso a ser falado junto a um auditório, seja nas assembleias ou nos tribunais, e por isso Aristóteles distingue os meios de persuasão, as argumentações ou provas (pisteis) em duas categorias: numa estão as provas não-técnicas (atechnoi), que são as leis, as testemunhas, os depoimentos extraídos sob tortura, os contratos e os juramentos, ou seja, provas preexistentes ao discurso do orador; noutra estão as técnicas ou artísitcas (entechnoi), provas (pisteis) pelo logos elaborado pelo orador, pelo ethos deste e pelo pathos do auditório.

Já o caráter técnico da dialética consiste em saber utilizar bem as argumentações (syllogismoi) (Tópicos 100 a21). Enquanto a dialética analisa os enunciados prováveis a partir da função designativa da linguagem, concluindo com isto a verossimilhança de tais enunciados, a retórica os investiga a partir das competências comunicativas da linguagem, concluindo sobre sua capacidade de persuasão (RACIONERO, Retórica de Aristóteles, 1994, p. 36).

É, pois, evidente que a retórica não pertence a nenhum gênero particular e definido, antes se assemelha à dialética. É também evidente que ela é útil e que sua função não é persuadir mas discernir os meios de persuasão mais pertinentes a cada caso, tal como acontece em todas as outras artes; de fato, não é função da medicina dar saúde ao doente, mas avançar o mais possível na direção da cura, pois também se pode cuidar bem dos que já não estão em condições de recuperar a saúde. (Retórica I 1355b)

A arte retórica não possui um único objeto ao qual se dedica, antes pode ser aplicada a várias questões e sua finalidade é encontrar os meios de persusão mais eficazes nos gêneros de discurso - deliberativo, epidítico e judiciário. A persuasão, contudo, não objetiva apenas o sucesso, como vemos em Protágoras, porque para Aristóteles ela também se relaciona com a verdade: "[...] a retórica é útil porque a verdade e a justiça são por natureza mais fortes que os seus contrários." (Retórica 
Linha D'Água (Online), São Paulo, v. 29, n. 2, p. 43-67, dez. 2016

I 1, 1355 a21-22). A capacidade persuasiva da retórica para o filósofo, inclusive, é maior quanto mais próximo se está do verdadeiro:

[...] quem melhor puder teorizar sobre as premissas - do que e como se produz um silogismo - também será o mais hábil em entimemas, [...] pois é próprio de uma mesma faculdade discernir o verdadeiro e o verossímil, já que os homens têm inclinação natural para a verdade e a maior parte das vezes alcançam-na. E, por isso, ser capaz de discernir [stochastikos echein] sobre o plausível [pros ta endoxa] é ser igualmente capaz de discernir sobre a verdade. (Retórica I 1, 1355 a10-18)

Estar próximo do verdadeiro indica o verossímil que, para Aristóteles, não é o que tem aparência de verdadeiro e, por isso conclui-se falso, mas, é aquilo que se aproxima do verdadeiro; devemos lembrar que o termo grego eikos, muitas vezes, traduzido como "provável" ou "verossímil", literalmente significa "semelhante", o que indica sua proximidade com o verdadeiro. A retórica é um método (hodos; Retórica I 1,1354 a8) que seleciona e justifica enunciados verossimilhantes (e por isso mesmo eles são persuasivos), pois a pistis é uma "espécie de demonstração" (apodeixis tis), cuja principal forma é o entimema, um silogismo de probabilidade, fundamentado nos endoxa: "Persuadimos, enfim, pelo discurso [via argumentos que têm como premissa os endoxa], quando mostramos a verdade ou o que parece verdade, a partir do que é persuasivo em cada caso particular." (Retórica I 2, 1356 a19-20)

Podemos ainda concluir que aquele que conhece bem a dialética também conhece bem os entimemas retóricos para o filósofo (1355 a3-14), e nisso consiste, como diz Berti, a analogia estrutural que existe entre dialética e retórica em Aristóteles. Este comentador observa ainda que o próprio Aristóteles percebe uma analogia entre a capacidade de apreender a verdade - da ciência ou filosofia -, e a capacidade de apreensão daquilo que se "assemelha à verdade", próprio da retórica, assim como há uma analogia entre a disposição para o verdadeiro (próprio da filosofia) e a disposição para as premissas "gerais" ou comuns (endoxa), das quais partem as argumentações dialéticas (Tópicos 100 b21 ss). Disso se conclui que a

16 De acordo com $Q$. Racionero, a raiz do vocábulo entimema, formada por en thymoi, indica a validade subjetiva das premissas. Aristóteles Retórica, p. 46. Thymos indica o "ânimo", "impeto", envolvendo o estado de alma. Cf. Retórica I 1. 
Linha D'Água (Online), São Paulo, v. 29, n. 2, p. 43-67, dez. 2016

analogia estrutural da retórica com a dialética torna a retórica análoga também da ciência (episteme), embora isto ocorra indiretamente, já que tal analogia se faz pelo operar da dialética assemelhar-se ao da episteme: ${ }^{17}$ "Não porque os fatos de que se ocupam tenham igual valor [retórica e ciência], mas porque os verdadeiros e melhores são pela sua natureza sempre mais aptos para os silogismos e mais persuasivos." (Retórica I 1, 1355 a36-38)

De maneira parecida com o tratamento que a dialética faz entre silogismo autêntico e silogismo aparente, a retórica trata do entimema autêntico e do entimema aparente: "que corresponde justamente à demonstração do verdadeiro aparente" (Retórica I 2, 1356 b16-18). O que caracteriza o entimema, ou as premissas da argumentação retórica de maneira semelhante ao silogismo dialético, é o verdadeiro "na maioria dos casos" [hos epi to poly], e nisso consiste o valor epistemológico dos endoxa para Aristóteles:

[...] atendendo a que nenhuma arte se ocupa do particular - por exemplo, a medicina, que não especifica o que é remédio para Sócrates ou Cálias, mas, para pessoas da sua condição (pois isso é que é próprio de uma arte, já que o individual é indeterminado e não objeto de ciência) -, tampouco a retórica teorizará sobre o provável para o indivíduo - por exemplo, para Sócrates ou Hípias -, mas sobre o que parece verdade para pessoas de certa condição, como também faz a dialética. (Retórica I 2, 1356 b30-34)

As premissas das argumentações retóricas - entimemas - são argumentações persuasivas por fundamentarem-se nos endoxa, e seu valor epistemológico está no fato dos endoxa coincidirem com o que é semelhante ao verdadeiro na maioria dos casos, ou seja, o verossimilhante (to eikos). É, portanto, dessa forma que Aristóteles estabelece o valor epistemológico ou valor de verdade das opiniões de tipo endoxa.

Já o verossímil (eikos) - provável, plausível -, aparece esclarecido na obra aristotélica sobre outra arte da linguagem, a Poética:

17 Cf. observa BERTI, 2002, p. 172-173. Lembremos que filosofia e episteme (ciência) são sinônimas em Aristóteles. Berti ainda recorda uma analogia posterior entre retórica e ciência: ambas são, como toda potência racional, potência de contrários, como, por exemplo, a arte da medicina, que tanto pode curar como envenenar o paciente. Id. Ibid. p. 175. Cf. também Metafísica IX 2. 
[...] a poesia é mais filosófica e tem um caráter mais elevado do que a história. É que a poesia expressa o universal, a histórica o particular. $\mathrm{O}$ universal é aquilo que certa pessoa dirá ou fará, de acordo com a verossimilhança ou a necessidade, e é isso que a poesia procura representar, atribuindo, depois, nomes às personagens. O particular é, por exemplo, o que faz Alcibíades ou que lhe aconteceu. (Poética 1451 b5-11)

Ser mais filosófica que a história não significa aqui que a poesia trate de verdades ou que não haja verdade nos fatos históricos. Estes são verdadeiros sim - recordando que o termo grego bistoria significa "investigação"-, mas tratam de fatos particulares, não necessariamente relacionados entre si, enquanto a poesia apresenta narrativas sobre assuntos que poderiam acontecer na maioria das vezes e, quando encadeados, tornam a poesia mais "científica" ou filosófica do que a história de acordo com Aristóteles.

$\mathrm{Na}$ Poética, a unidade da ação na poesia deve formar um todo (bolon) de maneira que, se suprimida ou deslocada qualquer uma de suas partes, essa supressão ou esse deslocamento provoque a desorganização desse todo. Cada parte que compõe a totalidade do enredo (mythos) deve formar um corpo tão coeso e interligado a ponto de totalidade e unidade serem inseparáveis, uma implicando a outra. $\mathrm{E}$ isso não ocorre com os fatos narrados pela história, ou se ocorre é algo raro.

São estes critérios, de unidade e de totalidade, que indicam o universal ( $k a$ thalou) da poesia em detrimento do particular da história, e a aproximação da poesia com a filosofia. Segundo Aristóteles, a narrativa histórica diz respeito ao já acontecido, enquanto que a narrativa poética se inscreve no campo do possível e do verossímil. Apesar do poeta e do historiador utilizarem-se do mesmo meio de expressão - a escrita em verso ou em prosa -, o conteúdo a que se referem demonstra suas diferenças: o historiador narra o sucedido e o poeta narra o que poderia ser dentro da ordem do verossímil e do necessário. Por encadear e ordenar os fatos e as ações no mythos, a poesia é considerada mais próxima da filosofia do que a história, e seu conteúdo ordenado revela sua universalidade (Cf. Poética 9, 1451 a36-1451 b10). Como lida com o plausível do "como se" composto pelo poeta, a poesia se distancia da filosofia, que lida com o que é verdadeiro (Cf. $M e-$ tafísica II 6, 1003 a15). 
Segundo Paul Ricoeur, para Aristóteles um período único de tempo, em que várias ações ocorrem, não constitui uma ação una, portanto, "o laço interno da intriga é mais lógico que cronológico” e, como observa Ricoeur, essa lógica não é a mesma da theoria, pois ela se refere a uma inteligibilidade própria do campo da praxis, significando ser ela vizinha da phronesis, ou seja, da inteligência da ação já que a poesia é um fazer sobre o fazer dos homens em ação, dos agentes. Mas esse fazer também não é de ordem ética, pois não é efetivo, é sim um fazer mimético (RICOEUR, 1994, p. 67-68). De acordo com Stephen Halliwell, o discurso mimético em Aristóteles está fora do dilema verdadeiro-falso, enquanto o discurso teórico, científico, deve ser considerado sob o aspecto do verdadeiro ou do falso (HALLIWELL, 2002, p. 155; HALLIWELL, 1998, p. 132-133). Mas esta afirmação não se sustenta plenamente pelo aspecto mimético da linguagem poética,já que isso não é exclusivo dela, pois as palavras, ou a própria linguagem, são consideradas miméticas por Aristóteles: "Assim, pois, os que a princípio iniciaram este movimento [do estilo e da recitação] foram, como é natural, os poetas, posto que as palavras são imitações [onomata mimemata estin] ${ }^{18}{ }^{18}$ A proximidade da poesia e da filosofia estaria, então, na ordenação de um todo, e o fato da poesia ser do campo do "como se" sublinha a diferença desta em face da filosofia. ${ }^{19}$

Quanto às argumentações retóricas, o provável ou verossímil (que é uma premissa plausível ou endoxon) é uma classe do contingente, ou seja, é um contingente que ocorre "na maioria das vezes", o que garante a proximidade ou semelhança com a verdade:

Com efeito, probabilidade é o que geralmente acontece [to os epi to poly ginomenon], mas não absolutamente, como alguns definem; antes versa sobre coisas que

18 Retórica III, 1404 a20-23. Tradução nossa a partir do texto grego da Loeb cotejada por sua tradução e pelas traduções de YEBRA e de SOUSA.

19 Ainda na Poética, ao comparar a narrativa da epopeia com a história, Aristóteles considera que esta além de sempre dizer respeito ao particular, é também narrativa casual, portanto, sem necessidade, probabilidade ou verossimilhança, já que se liga ao factual: "Também é manifesto que a estrutura da poesia épica não pode ser igual à das narrativas históricas, as quais têm de expor não uma ação única, mas um tempo único, com todos os eventos que sucederam nesses períodos a uma ou a várias personagens, eventos cada um dos quais está para os outros em relação meramente casual." Poética 23, 1459 a21-24. 
podem ser de outra maneira, e relaciona-se no que concerne ao provável como o universal se relaciona com o particular. (Retórica I 2, 1357 a31-b1)

Os entimemas retóricos apresentam outra premissa, os "signos" (semeia), e deles a conclusão pode ser necessária, enquanto que as premissas prováveis (eikota), apesar de constituírem a maioria das premissas dos entimemas, caracterizam-se por levarem a uma conclusão geral, não necessária. Apesar de alguns signos levarem a conclusões necessárias, e nesse caso, os signos são "provas" (tekmeria) de caráter irrefutável (alyta), há signos que não constituem provas e, portanto, são signos não necessários, refutáveis (lyta), como alguns casos de indução (Retórica I 2, 1357 b1-17), mesmo quando sua conclusão seja verdadeira (1357 a22-b25). Este último tipo de sinal "não guarda nenhuma relação com os endoxa”, como esclarece Berti (2010a, p. 378).

Tanto os entimemas retóricos quanto os silogismos dialéticos dizem respeito aos lugares (topoi), aos esquemas de argumentação comuns (koinoi). Ambas, retórica e dialética, são capacidades argumentativas calcadas em opiniões que apresentam a veracidade de premissas aceitas pela maioria ou pelos peritos, que são verdade na maioria das vezes. Em suma, a retórica é uma forma de racionalidade estruturada sobre argumentações dialéticas, e por causa desta estrutura apresenta caráter técnico, visto dizer respeito ao verossímil (Cf. BERTI, 2002, p. 185). Isso fica ainda mais evidente na distinção feita por Aristóteles dos entimemas:

Há duas espécies de entimemas: os demonstrativos [deiktika] de algo que é ou não é, e os refutativos [elenktika]; a diferença é igual à que existe na dialética entre refutação e silogismo. O entimema demonstrativo é aquele em que a conclusão se obtém a partir de premissas com as quais se está de acordo; o refutativo conduz a conclusões que o adversário não aceita. (Retórica II 22, 1396 b22-27)

Outra aplicação interessante da dialética para Aristóteles vai além de seu campo e do campo retórico, chegando às ciências, ao permitir o desenvolvimento de aporias opostas que possibilita ao pesquisador de uma dada ciência a dedução das consequências na verificação de qual solução conduz à contradição - e por isso deve ser evitada -, e qual solução não cai em contradição e pode ser aceita. Dessa forma, a dialética permite ao cientista chegar ao verdadeiro e ao falso, já 
Linha D'Água (Online), São Paulo, v. 29, n. 2, p. 43-67, dez. 2016

que a contradição é para Aristóteles sinal de falsidade. Tal aplicação da dialética está presente para Aristóteles nas chamadas "ciências verdadeiras" ou "ciências filosóficas", como a geometria, o modelo de ciência apodítica dos Segundos Analíticos, e nas ciências cujos fatos ocorrem casualmente, como a física e a ciência política ou ética. ${ }^{20}$

A metodologia dialética calcada nos endoxa consegue, assim, verificar ou indagar os princípios das ciências verdadeiras ou filosóficas, algo que elas próprias não podem fazer, pois é preciso indagar sobre suas proposições partindo dos endoxa de cada uma delas, tornando a dialética aristotélica uma verdadeira "via para os princípios" (BERTI, 2010b, p. 224-234). E, no caso das ciências anteriormente aludidas, nas quais não é possível a demonstração propriamente dita, a dialética ajuda no mesmo tipo de distinção entre verdadeiro e falso:

Depois do que precede, devemos dizer para quantos e quais fins é útil este tratado. Esses fins são três: o adestramento do intelecto, as disputas casuais e as ciências filosóficas. Que ele é útil como forma de exercício ou adestramento, é evidente à primeira vista. A posse de um plano de investigação nos capacitará para argumentar mais facilmente sobre o tema proposto. Para as conversações e disputas casuais, é útil porque, depois de havermos considerado as opiniões defendidas pela maioria das pessoas, nós as enfrentaremos não nos apoiando em convicções alheias, mas nas delas próprias, e abalando as bases de qualquer argumento que nos pareça mal formulado. Para o estudo das ciências filosóficas é útil porque a capacidade de suscitar dificuldades significativas sobre ambas as

20 "Tais coisas, isto é, as que são por natureza, ou sempre ou no mais das vezes vêm a ser de tal maneira, mas, entre as coisas que são por acaso ou pelo espontâneo, nenhuma vem a ser assim." (Física II 8, 198 b35-37 Tradução de Lucas Angioni. Campinas: IFCH/UNICAMP, 1999); "e ao falar de coisas que são verdadeiras apenas em sua maior parte [hos epi to poly] e com base em premissas da mesma espécie, só poderemos tirar conclusões da mesma natureza." (Ética a Nicômaco I 3, 1094 b2 1-22 Tradução de Leonel Vallandro e Gerd Bornheim da versão inglesa de W. D. Ross. São Paulo: Abril Cultural, 1973) Permanece um problema, como Berti considera ao final de seu artigo sobre o valor epistemológico dos endoxa, "saber se também a metafísica pode usar os endoxa como premissas para suas argumentações." (BERTI, $2010 a$, p. 384-387) Em outro lugar, Berti considera a discussão acerca das quinze aporias no Livro III da Metafísica um procedimento tipicamente dialético (2002, p. 81 ss.), interpretação partilhada por diversos comentadores. Para isso ver ainda PEREIRA, 2001, p. 355ss. Também em Metafísica IV, onde se discute os princípios de não contradição e do terceiro excluído, a análise é dialética. 
Linha D'Água (Online), São Paulo, v. 29, n. 2, p. 43-67, dez. 2016

faces de um assunto nos permitirá detectar mais facilmente a verdade e o erro nos diversos pontos e questões que surgirem. Tem ainda utilidade em relação às bases últimas dos princípios, usados nas diversas ciências, pois é completamente impossível discuti-los a partir dos princípios peculiares à ciência particular que temos diante de nós, visto que os princípios são anteriores a tudo o mais; é à luz das opiniões geralmente aceitas [endoxa] sobre as questões particulares que eles devem ser discutidos, e essa tarefa compete propriamente, ou mais apropriadamente, à dialética, pois esta é um processo de crítica onde se encontra o caminho que conduz aos princípios de todas as investigações. (Tópicos I 2)

Enfim, a dialética para Aristóteles permite desenvolver as aporias opostas de uma dada ciência, o que possibilita distinguir o verdadeiro e o falso onde há duas possibilidades de respostas de difícil solução - a aporia -, o que possibilita ao cientista desenvolvê-las para verificar o contraditório e o verdadeiro. Assim chegase a certo grau de certeza em ciências nas quais não é possível exatamente uma demonstração, e outra aplicação da dialética para as ciências é a análise de seus princípios, já que é algo que as ciências verdadeiras não podem fazer.

Finalizando o que vimos até aqui, dialética e retórica, assim como a própria ciência, não são distintas para Aristóteles pela estrutura, pois nas três temos o silogismo - científico, dialético e entimema -, estrutura que permite deduzir ou fazer inferência das premissas até chegarmos à conclusão, lembrando ainda que o verbo syllogeisthai significa "argumentar", ou seja, todas são artes da argumentação em que as opiniões de tipo endoxa desempenham importante papel na verificação do verdadeiro ou do verossímil, seu semelhante. Assim, os "em-doxa" (endoxa) constituem opiniões refinadas usadas nas argumentações das diversas formas de racionalidade teorizadas por Aristóteles, formas estas até hoje praticadas e nem todas redutíveis ao raciocínio lógico matemático, tão em voga (cf. BERTI, 2002, p. 187; p. XVI). 
Linha D'Água (Online), São Paulo, v. 29, n. 2, p. 43-67, dez. 2016

\section{Referências}

\section{Obras Completas e traduções}

ARISTÓTELES. Aristotle in Twenty-three Volumes. Cambridge-Mass./London: Harvard University Press. (The Loeb Classical Library)

. The Works of Aristotle: Selected Fragments. Translated by Sir David Ross. Oxford: Clarendon Press, 1952.

Ética a Nicômaco. Tópicos. Dos Argumentos Sofísticos. Metafísica (Livros I e II). Poética. Tradução AAVV. São Paulo: Abril Cultural, 1973. (Os Pensadores IV)

Retórica. Tradução e notas de M. Alexandre Jr., P. F. Alberto e A. N. Pena. Lisboa: Imprensa Nacional/Casa da Moeda, 1998.

. Retórica. Introdução, tradução e notas de Quintín Racionero. Madrid: Gredos, 1994.

Ética a Nicómaco. Ética Eudemia. Tradução de e Notas Emílio Lledó Íñigo. Madrid: Gredos, 1974.

Ética a Nicômaco. Tradução de António de Castro Caeiro. São Paulo: Atlas, 2009.

Poética. Tradução e Notas de Ana Maria Valente. Lisboa: Calouste Gulbenkian, 2004.

Poética. Tradução trilíngue de Valentín García Yebra. Madrid: Gredos, 1974.

Poética. Tradução, Prefácio, Introdução, Comentário e Apêndices de Eudoro de Sousa. Lisboa: Imprensa Nacional/Casa da Moeda, 1986.

. Politica. Tradução e Notas A. C. Amaral e C. C. Gomes. Lisboa: Vega, 1998.

Fisica. Livros I-II. Tradução de Lucas Angioni. Campinas: IFCH/UNICAMP, 1999.

Metafísica. Tradução trilíngue de Valentín García Yebra. Madrid: Gredos, 1990.

Metafísica. Prefácio de Sir David Ross. Tradução de Leonel Vallandro da versão inglesa de D.W. Ross. Porto Alegre: Globo, 1969.

MENEZES E SILVA, C. M. 0 conceito de doxa (opinião) em Aristóteles 
Linha D'Água (Online), São Paulo, v. 29, n. 2, p. 43-67, dez. 2016

. Tratados de Lógica (Organon): Categorias. Tópicos. Sobre las refutaciones sofísticas. Tradução de Miguel Candel Sanmartín. Madrid: Gredos, 1988.

Tratados de Lógica (Organon): Sobre la interpretación. Analíticos Primeiros. Analíticos Segundos. Tradução de Miguel Candel Sanmartín. Madrid: Gredos, 1994.

GÓRGIAS. Sobre o não-ente. Elogio de Helena. Tradução de Maria Cecília de Miranda Nogueira Coelho. Cadernos de Tradução, São Paulo, n. 4, p. 5-14, 1999.

DIÔGENES LAÊRTIOS. Vidas e doutrinas dos filósofos ilustres. Tradução Mário da Gama Kury. 2.ed. Brasília: UnB, 2008.

PLATÃO. Eutidemo. Tradução de Maura Iglésias. Rio de Janeiro: PUC-Rio/Loyola, 2011.

PLATÃO. Górgias. Tradução de Daniel R. N. Lopes. São Paulo: Perspectiva, 2011.

\section{Comentadores}

AUBENQUE, Pierre. "De l'egalité dês segments intermédiaires dans la ligne de la Republique", In Sophies Maietores, Homnage a Jean Pépin, 1992, 31-44.

BAILLY A. Dictionnaire Grec-Français. Paris: Hachette, 2010.

BERTI, Enrico. O valor epistemológico dos endoxa segundo Aristóteles. In Norvos estudos aristotélicos I: Epistemologia, lógica e dialética. Tradução de Élcio de Gusmão V. Filho. São Paulo: Loyola, 2010a.p. 370-387.

. "A antiga dialética grega como expressão da liberdade de pensamento e de expressão".

In Noros estudos aristotélicos I: Epistemologia, lógica e dialética. Tradução de Élcio de Gusmão V. Filho. São Paulo: Loyola, 2010a. p. 392-409.

. “Zenão de Eléia: inventor da dialética?”. In Novos estudos aristotélicos I: Epistemologia, lógica e dialética. Tradução de Élcio de Gusmão V. Filho. São Paulo: Loyola, 2010a. p. 411-431.

. No princípio era a maravilha. As grandes questões da filosofia antiga. Tradução de Fernando Soares Moreira. São Paulo: Loyola, $2010 b$. 
Linha D'Água (Online), São Paulo, v. 29, n. 2, p. 43-67, dez. 2016

Aristóteles no século XX. Tradução de Dion Davi Macedo. São Paulo, Loyola, 1997.

As razões de Aristóteles. Tradução de Dion Davi Macedo. 2. ed. São Paulo: Loyola, 2002. (Leituras Filosóficas)

CHERNISS, H. F. A Economia Filosófica da Teoria das Idéias. Tradução de Irley Franco. O que nos faz pensar. Rio de Janeiro: PUC, n. 2, 1990. p.

CONFORD, F. M. La Teoria Platónica del Conhecimento. Buenos Aires: Piados, 1968.

DINUCCI, Aldo Lopes. O elenchus como o principal instrumento da pedagogia socrática. Saberes, Natal-RN, v. 1, n. 1, dez. 2008. p. 5-16.

DÜRING, Ingemar. Aristóteles. Tradução de Barnabé Navarro. 2. ed. México: Universidad Nacional Autónoma de México, 1990.

GOLDSCHMIDT, V. Os diálogos de Platão: estrutura e método dialético. Tradução de Dion Davi de Macedo. São Paulo: Loyola, 2002.

HALLIWEL, Stephen. "Mimesis". In Aristotle's Poetics. With a new introdution. Chicago: The University of Chicago Press, 1998.p. 109-137.

"Inside and Outside the Work of Art: Aristotelian Mimesis Reevaluated". The Aesthetics of mimesis. Ancient texts $\mathcal{E}^{\circ}$ modern problems. Princeton: Princeton University Press, 2002. p. 151-176.

IGLÉSIAS, Maura. Platão: a descoberta da alma. Boletim do CPA, Campinas, n. 5/6, jan./dez. 1998.

KIRK, G. S.; RAVEN, J. E.; SCHOFIELD. Os fllósofos pré-socráticos. História crítica com selecção de textos. Tradução de Carlos Alberto Louro Fonseca. Lisboa: Calouste Gulbenkian, 2010.

MANSFIELD, Jaap "Fontes”. In LONG, A. A. (Org.) Primórdios da Filosofia. Tradução de Paulo Ferreira. Aparecida, SP: Idéias\& Letras, 2008. p. 74. (Companions \& Companions)

MOST, Glen. "The uses of the Endoxa. Philosophy and Rhetoric in the Rhetoric." In FURLEY, D.; NEHAMAS, A. (orgs.) Aristotle's Rhetoric. Philosophycal Essays. Princeton: Princenton University Press, 1994. p. 167-190. 
Linha D'Água (Online), São Paulo, v. 29, n. 2, p. 43-67, dez. 2016

PEREIRA, Oswaldo Porchat. Ciência e dialética em Aristóteles. São Paulo: UNESP, 2001.

PUENTE, Fernando Rey. A téchne em Aristóteles. Hypnos, ano 3, n. 4, p. 129-135

RICOEUR, Paul. “Entre retórica e poética: Aristóteles”. In $A$ metáfora viva. Tradução de Dion Davi Macedo. São Paulo: Loyola, 2000. (Leituras Filosóficas)

"O tecer da intriga: uma leitura da Poética de Aristóteles". In Tempo e narrativa. Tomo

I. Tradução de Constança Marcondes César. Campinas: Papirus, 1994.

ROBINSON, R. Plato's earlier dialectic. Oxford: Oxford University Press, 1966.

Recebido: 30/08/2016.

Aprovado: 18/09/2016. 